\title{
Knowledge and menstrual hygiene practice among adolescent school girls in southern Ethiopia: a cross-sectional study
}

Zelalem Belayneh ${ }^{*}$ and Birhanie Mekuriaw

\begin{abstract}
Background: Menstruation is a normal physiological process of females at their reproductive age. However, it is surrounded with social taboos and supernatural beliefs. The poor knowledge and understanding of menstruation may lead to unsafe hygienic practice that intern increases the risk of reproductive and genito-urinary tract infections, cervical cancer, school drop-out, poor academic performance and overall poor quality of life. Despite such clinical and academic effects, the knowledge and hygienic practice of adolescent girls towards menstruation is not well addressed in Ethiopia, particularly among school adolescent girls. Therefore, the main objective of this study was to assess the knowledge and menstrual hygiene practice among adolescent school girls in southern Ethiopia.

Methods: This was an institutional based cross-sectional study conducted at Gedeo zone high schools among 791 randomly selected adolescent girls using multi stage sampling technique. Data were collected using interviewer administered questionnaire. The collected data were entered to EPI-INFO (soft ware) and exported to SPSS version 20 for analysis. Bivariable and multivariable logistics analyses were computed to identify factors associated with the poor menstrual hygienic practice. During bi-variable analysis, variables with $P$-values of less than 0.25 were entered to multivariable model for further analysis. In the final model, $P$-value of less than 0.05 was used as a base to identify factors having a statistically significant association with poor menstrual hygiene practice at corresponding 95\% confidence interval.

Result: From a total of 791 adolescent girls participated in this study, 68.3\% had poor knowledge of menstruation. About $48.1 \%$ of school girls used absorbent materials, and $69.5 \%$ clean their external genitalia. Generally, $60.3 \%$ of girls had poor menstrual hygienic practice. Age less than 15 years $[\mathrm{OR}=1.71: 95 \% \mathrm{Cl}(1.22,2.39)]$, longer days of menstrual flow $[\mathrm{OR}=2.51: 95 \% \mathrm{Cl}(1.66,3.80)]$ and poor knowledge of menses $[\mathrm{OR}=1.48: 95 \% \mathrm{Cl}(1.04,2.1)]$ had a significantly associated with poor menstrual hygiene practice.
\end{abstract}

Conclusion: Majority of adolescent school girls had poor knowledge regarding menstruation and their hygienic practices are incorrect. This demonstrates a need to design acceptable awareness creation and advocacy programs to improve the knowledge and promote safe hygienic practice of adolescent school girls during menstruation.

Keywords: Menstruation, Hygienic practice, Menses, Cross-sectional study, Adolescents

\footnotetext{
* Correspondence: zelalembe45@gmail.com

Department of Psychiatry, College of Health and Medical Science, Dilla

University, Dilla, Ethiopia
}

(c) The Author(s). 2019 Open Access This article is distributed under the terms of the Creative Commons Attribution 4.0 International License (http://creativecommons.org/licenses/by/4.0/), which permits unrestricted use, distribution, and reproduction in any medium, provided you give appropriate credit to the original author(s) and the source, provide a link to the Creative Commons license, and indicate if changes were made. The Creative Commons Public Domain Dedication waiver (http://creativecommons.org/publicdomain/zero/1.0/) applies to the data made available in this article, unless otherwise stated. 


\section{Background}

Menstruation is a universal and normal phenomenon during the reproductive age of females [1,2]. The onset of menses takes place during adolescent period in which dominant physiological and emotional changes take place [2, 3]. Adolescent is an essential period where females are preparing and adjusting themselves to manage their menstrual bleeding in safe and clean way [3, 4]. This is also the ideal time that girls often join different environments including high schools and tried to plan for their next adulthood life [3].

However, most adolescent girls (girls with age ranges of 10 to 19 years old) enter to their puberty stage (maturity) without preparing themselves due to the shortage of adequate information [5]. Most women are uncomfortable to discuss regarding "menses" as it is has a social taboo and adolescent girls could not have access to gain adequate information $[4,6]$. Even the little information they receive most commonly from religious institutions, peers, family member is often selective and surrounded by misperceptions [7]. For example, people in developing countries like Ethiopia often perceive menstruation as something happened as a result of being cursed, a sign of diseases, punishment from God, a lifelong process and others [7-11]. As a result, adolescent girls perceive menstruation as something embarrassing that should be kept hidden [9-12]. This can increase the vulnerability of adolescent girls to have mental, emotional and physical problems [13-15]. These conditions further impair the daily activities, academic performance, school attendance, and social relationships of adolescent girls $[16,17]$.

The view in which girls perceive towards menstruation also affects their hygienic practice during their menstrual bleeding [18]. Women with better understanding of menses often have safe and clean way of managing their menstrual bleeding and vice versa $[9,18,19]$. It is uncovered that poor menstrual hygiene practice can be a reason for reproductive and genitor-urinary tract infection, cervical cancer, school absenteeism, or drop-out, poor academic performance, lower self-esteem and poor quality of life [20]. Moreover, girls have also often experienced feelings of fear, confusion and shame during their menstruation period as a result of smell, leakage, staining of clothes and dropping of sanitary materials during their class schedules [21]. This can have also a negative impact on the concentration, class participation and confidence of their studies [22].

Although poor knowledge and unsafe menstrual hygiene practice have such considerable clinical implications for the girls themselves and their future off springs [19], knowledge of adolescent girls regarding menstruation is poor and their hygienic practices are not correct, particularly with lower socio-economic contexts [7, 19].
It has been reported that $40-45 \%$ of adolescent school girls have poor knowledge and unsafe hygienic practice of their menstrual bleeding [5]. This might have a clinical implication to integrate the promotion of menstrual hygienic practice in the health care system [21] and comprehensive efforts including policy implication are needed to improve girls' knowledge and safe hygienic practices towards menstruation right from her adolescent period [21, 22].

Despite safe menstrual hygienic practices can have a paramount importance to help millions of women suffering from such complicated and complex problems [23], it is the missed opportunity to address the level of understanding and hygienic practice of menstruation among girls earlier from their adolescent age in many developing countries, including Ethiopia [24, 25]. Little available studies in Ethiopia had no a particular focus of adolescent school girls' knowledge and menstrual hygiene practice. Moreover, there is a need to re-examine the association between poor menstrual hygienic practice (PMHP) and obstetric and gynecological factors among adolescent school girls. This is unrecognized and unaddressed public health concern in developing countries like Ethiopia. Therefore, this study was aimed to assess the Knowledge and menstrual hygiene practices of adolescent school girls in Gedeo zone. The result of this study might have a supreme clinical importance and might help for planning, policy preparation and developing appropriate intervention mechanisms. Furthermore, the findings of this study will be used as baseline information for further research works.

\section{Methods}

\section{Study design, period and setting}

This was an institutional based cross sectional study conducted from May 1st/2018 to February 1st/2019 among Gedeo zone high school girls. Gedeo is one of the eleven zones in South Nation, Nationality and Peoples' Regional (SNNPR) states of Ethiopia. Dilla is the zonal town of Gedeo people located at $359 \mathrm{~km}$ south from Addis Ababa (the capital city of Ethiopia). The zone is administrated in to six districts and two town administrations. In the zone, there are about 25 high schools in which a total of 2351 adolescent girls are enrolling.

\section{Sample size and sampling}

We used a single population proportion formula to determine the required sample size for this study. The assumptions made during the sample size calculation was $P=39.9 \%$ (prevalence of poor knowledge towards menstruation) based on a study done in Jimma [25], 95\% confidence interval (CI) and 5\% margin of error. By considering a design effect of 2 and 10\% non-response rate, the total sample size was 806 . 
Multi stage sampling technique was used to select study participants. First, six high schools were randomly selected from a total of twenty five high schools found in Gedeo zone. Then, the calculated sample size was proportionally allocated to randomly selected high schools based on the population size. In the second stage, systematic random sampling technique was used in each of randomly selected high schools using a sampling interval (K). The sampling interval $(\mathrm{K})$ was calculated by dividing the total number of eligible adolescent girls to the proportionally allocated samples. Student who had menstrual flow experience and having least two consecutive menstrual cycles within the last 2 months were included so as to minimize recall bias. The first participant was selected between 1 and $\mathrm{K}$ using lottery method and "K" value was consequently added until the allocated samples size was addressed.

\section{Data collection instruments and procedures}

Data were collected using structured and interviewer administered questionnaire. The questionnaire was developed from different literatures and contextually adapted to the cultural norms of the study area (Additional file 1). The questionnaire had different section consisting of socio-demographic profile, obstetric and gynecological related characteristics, questions used to assess knowledge of adolescent girls towards menstruation, and questions used to measure hygienic practices of menstruation.

Knowledge of adolescent school girls regarding menstruation was evaluated using a series of 20 Likert scale questions adopted from different literatures $[3,8,11,22$, $26,27]$. The responses of each 20 item questions had a range of scores from 0 to $3(0=$ strongly disagree, $1=$ disagree, $2=$ agree, $3=$ strongly disagree). The questions had both positively and negatively worded items regarding menstruation, and negatively worded statements were scored reversely. Individuals with a total sum score of 30 (mean score) and above were considered as having a good knowledge regarding menstruation.

The menstrual hygienic practices of adolescent school girls were evaluated using a ten item "Yes" or "No" questions. The response of each item was scored as "1" for correct answers and " 0 " for false responses. The total sum score of the tool ranges from 0 to 10 . The tool has been also used by another study conducted in Jimma University [25] and showed a good internal consistency with Cronbach alpha of 0.87 in this study. Girls with a total sum score of less than $50 \%$ (5 points) were considered as having a poor menstrual hygiene practice. The socio-demographic, obstetrics and gynecological and academic related characteristics were also recorded through structured interview.

All contents of the questionnaire was first prepared in English and translated to the local language (Gedeufa) and back to English to check its consistency. The Gedeufa version of the questionnaire was also pretested among 40 adolescent female students which could not be included in the actual data collection to check its understandability and ability to address study objectives. Based on the pretest result, minor modification was done regarding the content of the questionnaire and the expression of some terminologies.

Six data collectors (clinical nurses) and two supervisors (MSc level reproductive health professionals) were participated in the data collection after attending 2 days of training regarding the contents of the questionnaire and the data collection procedures. Before the interview, written consent was obtained from all participants above the age of 16. For minor participants (less than 16 years of age), consent was obtained from the parents/guardians on the behalf of participants under the age of 16 years old after providing a brief explanation about the purpose and objectives of the study. It is already known that menstruation is a sensitive issue surrounded by social taboo and supernatural perceptions. Females, particularly adolescent girls often afraid of discussing topics related menstruation. Therefore, we recruited clinical nurses for data collection by considering that clinical nurse can have better experience to communicate people regarding sensitive topics with therapeutic relationship.

\section{Operational definitions}

An adolescent is defined as a student with age range of 10 to 19 years old.

Early adolescent stands for individuals with age ranges of 10 to 14 years old.

Late adolescent refers to individuals whose age is between 15 and 19 years old.

Homemade absorbents in this study refers to noncommercially made sanitary materials prepared by family members or girls themselves for the purpose of menstrual hygiene practice.

Social taboo refers to the status in which the community wrongly assigns for females with menstrual flow and menstruation itself.

Puberty refers to the developmental stage of adolescents in which they start to show secondary sexual characteristics.

\section{Data analysis and interpretation}

The collected data were first checked for its completeness and consistency. The data then, entered to EPI-info version 3.5 (soft ware) and exported to the Statistical Package for Social Science (SPSS) version 20 for analysis. Descriptive statistics was computed to measure the level of knowledge and hygienic practice towards menstruation. We used bivariable and multivariable logistic analysis to identify factors associated with the poor menstrual hygiene practice of 
adolescent school girls. All variables with $P$-values less than 0.25 during bivariable analysis were entered together to a multivariable analysis to control possible cofounders. Accordingly, age, residency, living arrangement, duration of menstrual flow, age at menarche and knowledge regarding menses had $P$-values of less than 0.25 and entered to multivariable analysis. In the final model, lower age, longer duration of menses flow and poor knowledge towards menstruation were found to have statistically significant association with poor menstrual hygiene practice with $P$-values of less than 0.05 . The strength of the association was also measured by odds ratio with corresponding 95\% confidence interval (CI).

\section{Results}

From a total of 806 adolescent school girls invited to participate, 791 completed the interview with a response rate of $98.1 \%$. The mean $( \pm$ SD) age of respondents was $16.3( \pm 4.7)$ years with a minimum and maximum age ranges of 10 and 19 years. More than half, (58.3\%) were Gedeo in their ethnicity and $32.2 \%$ of adolescent school girls were living with their own parents (Table 1).

\section{Obstetric and gynecological related factors}

Large proportions, 615 (77.7\%) of adolescent school girls in Gedeo zone mentioned that they have experienced dysmenorrhea (severe pain during the menstruation) at least once within the last three conscequitave menstrual cycles. More than half, (67.6\%) have experienced their menarche (onset of first menses) within the age range of $12-15$ years, and $59.7 \%$ had irregular menstrual cycles (Table 2).

\section{Source of information regarding menstruation}

About $27.7 \%$ of adolescent girls did not have information regarding menstruation and its hygienic practice before their menarche. Of $72.3 \%$ school girls having menses related information before the onset of their menses, 38.3\% mentioned their mother as the main source of information and $16.3 \%$ got such information from their peers. Relatives, teachers, media and others were also mentioned as sources of information related to menstrual bleeding and its safe management by $6.4,2.4$, 7.6 and $1.3 \%$ of girls having information, respectively.

\section{Knowledge of adolescent girls towards menses}

There were numerous supernatural and traditional perceptions and beliefs attributed by adolescent school girls towards menstruation. "Disease as a cause of menses flow" and "Menses as a lifelong process" were common misconceptions endorsed by 51.8 and $50.2 \%$ adolescent girls, respectively. Generally, $68.3 \%$ of adolescent school girls in Gedeo zone had poor knowledge regarding menstrual bleeding (Table 3).
Table 1 Sociodemographic characteristics of adolescent girls at Gedeo zone high schools, Southern Ethiopia 2019 ( $n=791)$

\begin{tabular}{|c|c|c|c|}
\hline Variables & Categories & Frequency & Percentage \\
\hline \multirow[t]{2}{*}{ Age } & $\leq 15$ years & 118 & 14.9 \\
\hline & $>15$ years & 573 & 85.1 \\
\hline \multirow[t]{3}{*}{ Living with } & Parents & 290 & 31.3 \\
\hline & Relatives & 253 & 27.3 \\
\hline & Peers & 215 & 23.2 \\
\hline \multirow[t]{2}{*}{ Residency } & Town & 243 & 30.7 \\
\hline & Rural & 548 & 69.3 \\
\hline \multirow[t]{4}{*}{ Religion } & Orthodox & 206 & 26.0 \\
\hline & Protestant & 461 & 58.3 \\
\hline & Muslim & 64 & 8.1 \\
\hline & Others & 60 & 7.6 \\
\hline \multirow[t]{5}{*}{ Ethnicity } & Gedeo & 409 & 51.7 \\
\hline & Oromo & 182 & 23.0 \\
\hline & Amhara & 133 & 16.8 \\
\hline & Guragie & 25 & 3.2 \\
\hline & Others & 42 & 5.3 \\
\hline \multirow[t]{3}{*}{ Birth order } & First & 285 & 36.0 \\
\hline & In between & 326 & 41.2 \\
\hline & Last & 180 & 22.8 \\
\hline \multirow[t]{5}{*}{ Maternal education } & Unable to read and write & 278 & 35.1 \\
\hline & Able to read and write & 138 & 17.4 \\
\hline & Primary & 213 & 26.9 \\
\hline & Secondary & 73 & 9.2 \\
\hline & Diploma and above & 89 & 11.3 \\
\hline \multirow[t]{5}{*}{ Paternal education } & Unable to read and write & 202 & 25.5 \\
\hline & Able to read and write & 212 & 26.8 \\
\hline & Primary & 271 & 34.3 \\
\hline & Secondary & 44 & 5.6 \\
\hline & Diploma and above & 62 & 7.8 \\
\hline \multirow[t]{2}{*}{ Family structure } & Nuclear & 538 & 68.0 \\
\hline & Extended & 253 & 32.0 \\
\hline
\end{tabular}

\section{Hygienic practice of adolescent school girls}

Nearly one third, (33.9\%) of adolescent school girls did not use sanitary pads during their menstruation period. About $42.4 \%$ were using commercially made sanitary pads, and 23.7\% used homemade absorbents (dry clothes, double pants, sponges...). More than half, (69.5\%) of students clean their external genitalia with water and soap. Generally, $60.3 \%$ of girls found to have poor menstrual hygiene practice with $95 \% \mathrm{CI}(56.9,63.6)$ (Table 4).

\section{Factors associated with menstrual hygiene practice}

Bivariable and multivariable logistic analyses were done to identify factors associated with menstrual hygiene 
Table 2 Obstetric and gynecological related characteristics of adolescent girls at Gedeo zone high schools, southern Ethiopia, $2019(n=791)$

\begin{tabular}{llll}
\hline Variables & Categories & Frequency & Percentage \\
\hline Age of menarche & $<12$ years & 195 & 24.7 \\
& 12-15 years & 535 & 67.6 \\
& $>15$ years & 61 & 7.7 \\
Regularity of menses & Irregular & 472 & 59.7 \\
& Regular & 319 & 40.3 \\
Family history of dysmenorrhea & No & 509 & 64.3 \\
& Yes & 282 & 35.7 \\
Duration of menses flow & $<3$ days & 198 & 25.0 \\
& $3-5$ days & 503 & 63.6 \\
Pain during menstruation & $>5$ days & 90 & 11.4 \\
& No & 171 & 22.3 \\
\hline
\end{tabular}

practice. Accordingly, lower age, longer duration of menses flow and poor knowledge towards menstruation had statistically significant association with the poor menstrual hygiene practice (Table 5).

\section{Discussion}

Adolescence is recognized as a special critical period of females in which significant hormonal and emotional changes take place including their first menstrual onset [5]. Although menstruation is such a normal physiological process in females reproductive age, it is surrounded by taboos and supernatural perceptions [11]. As a result, many adolescent girls could not have the access to get adequate information regarding menstruation and its hygienic practice, and they often join to their menarche without preparing themselves, particularly in rural areas [8]. This might result in adverse health outcomes and poor academic performance of adolescent school girls [3].

In the current study, $68.3 \%$ of adolescent school girls in Gedeo zone had poor knowledge regarding the bleedings of menses. This is in line with other similar studies

Table 3 Knowledge regarding menstrual bleeding among adolescent girls in Gedeo zone high schools, Southern Ethiopia, 2019

\begin{tabular}{|c|c|c|c|c|c|}
\hline \multicolumn{2}{|c|}{ Question } & Strongly disagree(0) & Disagree(1) & Agree(2) & Strongly agree( 3 ) \\
\hline \multicolumn{6}{|c|}{ Menses } \\
\hline 1 & It is a normal phenomena & $8.0 \%$ & $5.9 \%$ & $10.4 \%$ & $75.5 \%$ \\
\hline 2 & It is unique to females & $24.7 \%$ & $17.7 \%$ & $6.8 \%$ & $50.8 \%$ \\
\hline 3 & Life long & $3.03 \%$ & $20.5 \%$ & $3.2 \%$ & $46.0 \%$ \\
\hline 4 & It is a lifelong process & $27.1 \%$ & $16.6 \%$ & $6.2 \%$ & $50.2 \%$ \\
\hline 5 & It will be stopped after initiation of sexual intercourse & $31 . .6 \%$ & $13.5 \%$ & $15.3 \%$ & $18.6 \%$ \\
\hline 6 & It is a sign of conception & $61.8 \%$ & $11.0 \%$ & $12.4 \%$ & $14.8 \%$ \\
\hline 7 & It has foul smell & $13.5 \%$ & $13.1 \%$ & $13.8 \%$ & $59.5 \%$ \\
\hline 8 & It is pathological & $58.9 \%$ & 8.05 & $11.8 \%$ & $21.4 \%$ \\
\hline \multicolumn{6}{|c|}{ Sources of bleeding } \\
\hline 9 & Uterus & $39.1 \%$ & $52 \%$ & $23.1 \%$ & $32.6 \%$ \\
\hline 10 & Bladder & $41.8 \%$ & $8.3 \%$ & $18.5 \%$ & $31.4 \%$ \\
\hline 11 & Vagina & $22.8 \%$ & $18.5 \%$ & $11.5 \%$ & $47.3 \%$ \\
\hline 12 & Abdomen & $40.3 \%$ & $13.5 \%$ & $20.5 \%$ & $25.7 \%$ \\
\hline \multicolumn{6}{|c|}{ Causes of menses } \\
\hline 13 & Hormonal & $33.9 \%$ & $10.7 \%$ & $18.6 \%$ & $36.8 \%$ \\
\hline 14 & Diseases & $51.8 \%$ & $11.6 \%$ & $16.3 \%$ & $20.7 \%$ \\
\hline 15 & Curse & $51.1 \%$ & $10.5 \%$ & $8.7 \%$ & $27.7 \%$ \\
\hline \multicolumn{6}{|c|}{ Which is good to be done during menstruation } \\
\hline 16 & Not allowed touch others during menstruation & $51.1 \%$ & $11.9 \%$ & $22.5 \%$ & $14.5 \%$ \\
\hline 17 & Not allowed to go to kitchens during menses & $53.2 \%$ & $12.8 \%$ & $13.7 \%$ & $20.4 \%$ \\
\hline 18 & It is not good to discus about menses & $50.1 \%$ & $10.7 \%$ & $13.3 \%$ & $25.9 \%$ \\
\hline 19 & Activities done by menstruating woman are not blessed & $39.6 \%$ & $15.7 \%$ & $22.4 \%$ & $224.4 \%$ \\
\hline 20 & Being free from menses is a fate & $37.7 \%$ & $17 . \%$ & $22.3 \%$ & $22.5 \%$ \\
\hline
\end{tabular}


Table 4 Menstrual hygiene practices of adolescents girls at Gedeo zone high schools, Southern Ethiopia, $2019(n=791)$

\begin{tabular}{|c|c|c|c|}
\hline \multicolumn{2}{|l|}{ Practice related questions } & Frequency & Percentage \\
\hline \multicolumn{2}{|c|}{ Using absorbent materials during menstruation } & 523 & 66.1 \\
\hline \multicolumn{2}{|c|}{ Using commercially made sanitary pad during menstruation } & 336 & 42.4 \\
\hline \multicolumn{2}{|c|}{ Change pads or cloths more than three times a day during menstruation } & 494 & 62.4 \\
\hline \multicolumn{2}{|l|}{ Using clean clothes with soap and water } & 151 & 19.1 \\
\hline \multicolumn{2}{|l|}{ Dries cloths in sunlight } & 375 & 47.4 \\
\hline \multicolumn{2}{|c|}{ Cleans external genitalia during menstruation } & 517 & 65.3 \\
\hline \multicolumn{2}{|c|}{ Disposes the pads by wrapping with paper } & 246 & 30.0 \\
\hline \multicolumn{2}{|c|}{ Washes bath daily with soap during menstruation } & 446 & 56.4 \\
\hline \multicolumn{2}{|c|}{ Cleaning of external genitalia with water and soap during menstruation } & 550 & 69.5 \\
\hline \multicolumn{2}{|l|}{ Disposes used sanitary pads in dustbin } & 354 & 44.7 \\
\hline \multirow[t]{2}{*}{ Over all menstrual hygiene practice } & Good & 314 & 39.7 \\
\hline & Poor & 477 & 60.3 \\
\hline
\end{tabular}

done in Southern Ethiopia (60.1\%) [25] and Nigeria which states that perceptions of menstruation are poor and practices are often unsafe among adolescent school girls in Nigeria [9]. However, the finding of the current study showed a better knowledge towards menstruation among adolescent school girls as compared to a similar study done in India, which revealed that $71.3 \%$ of female students had poor knowledge regarding their menstruation [8]. The possible explanation for this discrepancy might be the measurement techniques studies used to assess level of knowledge and the socio-cultural differences of study participants.
Regarding hygienic practices of menstrual bleeding, this study showed that nearly half (33.9\%) of girls did not use sanitary pads during menstruation and $60.3 \%$ of adolescent school girls were identified as having a poor menstrual hygiene practice in general. This is supported by other studies conducted in Northwest Ethiopia [26] and Tehran district [22] stating that adolescent girls had different traditional and supernatural perceptions regarding menstruation and their hygienic practice was not safe. The finding of this study is also in line with findings of studies of western Ethiopia (60.1\%) [27], Nigeria (55.7\%) [9] and India (64.0\%) [8]. This can have

Table 5 Bivariable and multivariable analysis of factors associated with poor menstrual hygiene practice among adolescent girls at Gedeo zone high schools, Southern Ethiopia, $2019(n=791)$

\begin{tabular}{|c|c|c|c|c|c|}
\hline \multirow[t]{2}{*}{ Variables } & \multirow[t]{2}{*}{ Categories } & \multicolumn{2}{|c|}{ Hygienic practice } & \multirow[t]{2}{*}{ COR 95\% C1 } & \multirow[t]{2}{*}{ AOR 95\% Cl } \\
\hline & & Good & Poor & & \\
\hline \multirow[t]{2}{*}{ Age } & $<15$ years & 105 & 113 & $1.61(1.18,2.21)$ & $1.71(1.22,2.39)^{* *}$ \\
\hline & $\geq 15$ years & 209 & 364 & 1 & 1 \\
\hline \multirow[t]{2}{*}{ Residency } & Rural & 217 & 331 & $1.01(0.74,1.38)$ & $1.06(0.77,1.47)$ \\
\hline & Town & 97 & 146 & 1.00 & 1.00 \\
\hline \multirow[t]{4}{*}{ Living with } & Parents & 107 & 146 & 11 & 1 \\
\hline & Relatives & 96 & 128 & $0.97(0.67,1.40)$ & $1.00(0.69,1.47)$ \\
\hline & Peers & 63 & 109 & $1.26(0.85,1.88)$ & $1.29(0.85,1.95)$ \\
\hline & Alone & 48 & 94 & $1.43(0.93,2.2)$ & $1.42(0.912 .22)$ \\
\hline \multirow[t]{3}{*}{ Duration of menses flow } & $<3$ days & 97 & 94 & 1 & 1 \\
\hline & $3-5$ days & 135 & 185 & $1.41(0.98,2.07)$ & $1.37(0.95,1.99)$ \\
\hline & $>5$ days & 82 & 198 & $2.49(1.69,3.65)$ & $2.51(1.66,3.80)^{* * *}$ \\
\hline \multirow[t]{2}{*}{ Knowledge towards menses } & Good & 209 & 326 & $1.28(0.92,1.78)$ & $1.48(1.04,2.1)^{*}$ \\
\hline & Poor & 17 & 44 & $2.12(1.13,3.98)$ & $1.64(0.85,1.95)$ \\
\hline \multirow[t]{3}{*}{ Age at menarche } & $<12$ years & 17 & 44 & $1.22(0.90,1.66)$ & $1.05(0.76,1.45)$ \\
\hline & $12-15$ years & 209 & 326 & $1.34(0.71,2.43)$ & $1.12(0.13,2.34$ \\
\hline & $>15$ years & 88 & 107 & 1 & 1 \\
\hline
\end{tabular}

${ }^{*} P$-value $<0.05,{ }^{* *} P<0.01,{ }^{* * *} P<0.001$ 
a clinical implication for the development and adaptations of contextualized and culturally validated measurement techniques and interventional approaches for adolescent school girls. Moreover, integration of menstrual hygiene promotion in different health care systems and female clubs in schools is also recommended.

However, studies conducted in Persian [21] and Kuwait [17] showed better hygienic practices of adolescent school girls towards menstruation than the finding of the current study. This is possibly explained by the fact that girls in Ethiopia are more attributed by supernatural and cultural perceptions and beliefs regarding menstruation that may restrict them to discuss topics regarding menses and hinder their safe hygienic managements. The other possible explanation for the discrepancy of this result might be due to the economical constraints of Ethiopian adolescent girls to buy commercially made sanitary pads needed for menstrual hygiene practice [4]. This demonstrates a need to provide or show means to access sanitary pads for adolescent school girls with economical constraints.

The second objective of this study was to identify factors associated with hygiene practices of adolescent school girls. Accordingly, the odds of having poor menstrual hygiene practice among adolescent school girls with longer duration of menstrual flow were 2.51 times higher as compared to girls with shorter duration of menstrual flow. The possible explanation for this association might be due to the fact that girls with longer duration of menstrual flow may have economical constraints to buy commercially made absorbents for longer time [26]. In addition, the longer duration of menstrual flow may affect the psychological and emotional states of girls which may further diminish their motivation and commitment to perform safe hygienic practices [22].

It is investigated that knowledge towards menstruation have significant associations with menstrual hygienic practices of girls [27-29]. The findings from the current study also confirmed this explanation by showing that girls with poor knowledge regarding menstrual flow were 1.48 more likely to practice their menstrual hygiene incorrectly. This is possibly due to the effects of cultural beliefs and social taboo regarding menstruation and its hygienic practices attributed by the community they live $[19,30,31]$.

Similarly, the odds of poor menstrual hygiene practice among adolescent school girls with age less than 15 years were increased by 1.71 times as compared to girls whose age was equal or greater than 15 years. This is possibly explained by the fact that girls with elder age can have a better opportunity to share more information, gain adequate knowledge regarding menstrual hygiene, and prepare themselves to demonstrate safe hygienic practice during their menstruation period as compared to girls with lower ages [31, 32].

\section{Strength and limitations of the study}

This study was conducted using intensive and culturally adapted tools. The study also tried to evaluate the knowledge and hygienic practices regarding menstruation in a private circumstance by recruiting female data collectors to minimize social desirability bias. However, this study has limitation. First, the cross-sectional nature of the study design might not show the cause and effect relationships between study variables. Second, this study follows only quantitative data collection, and it is not triangulated by mixed approaches. Therefore, further longitudinal and mixed approach study design with more exhaustive and mutually exclusive categories of variables is recommended.

\section{Conclusions}

Majority of adolescent school girls had poor knowledge regarding menstruation and their hygienic practices are incorrect. Lower age, longer duration of menses flow and poor knowledge towards menstruation were significant correlates of poor hygienic practice. This demonstrates a need to design acceptable awareness creation and advocacy programs for adolescent school girls and the public to improve the knowledge and safe hygienic practice of their menstruation flow.

\section{Supplementary information}

Supplementary information accompanies this paper at https://doi.org/10. 1186/s12889-019-7973-9.

Additional file 1. Interview guide used for the data collection of this study.

\section{Abbreviations}

AOR: Adjusted Odds Ratio; Cl: Confidence Interval; COR: Crude Odds Ratio; MHP: Menstrual Hygiene Practice; MSc: Masters of Science; PMHP: Poor Menstrual Hygiene Practice; RTI: Reproductive Tract Infections; SD: Standard Deviation; SPSS: Statistical Packages for Social Sciences

\section{Acknowledgments}

We would like to acknowledge the Institutional Review Board of Dilla University for ethical approval. Our deepest gratitude also goes study participants, data collectors and all staffs working at Gedeo zone high schools for their dedicated cooperation.

\section{Authors contributions}

ZB conceived the topic, developed the proposal, and participated in the data collection, analysis and manuscript preparation. BM also took major roles in the data collection, analysis, write up and revision. Both authors gave final approval for this version of the manuscript to be considered for publication.

\section{Funding}

There was no specific fund secured for this research.

Availability of data and materials

All data and materials of this study is available and can be accessed from Zelalem Belayneh (corresponding author) with the email address of "zelalembe45@gmail.com". 


\section{Ethics approval and consent to participate}

Prior to the data collection, ethical clearance was obtained from the Institutional Review Board of Dilla University, College of Health and Medical Science with reference number of (Ref. No: DU-4-8-208). Before the interview, written consent was obtained from all participants above the age of 16 years. For minor participants (less than 16 years of age), consent was obtained from the parents or guardians on the behalf of participants under the age of 16 years old after providing a brief explanation about the purpose and objectives of the study. Participants were also informed as there will not any risk as a result of their participation and the confidentiality of the collected information will be kept well. They were also informed that they have the right to refuse or withdraw their participation at any time they want, and no any harm could be imposed towards them due to their refusal. For participants under 16 years old, written informed consent was obtained from their parents or guardians in addition to assent obtained from girls themselves. During the data collection, personal identifiers such as name and phone numbers of the participants were not recorded to keep confidentiality rather numbers were assigned for coding purpose. The collected information were coded and kept confidential.

\section{Consent for publication}

Not applicable

\section{Competing interests}

The authors declare that they have no competing interests.

Received: 9 September 2019 Accepted: 19 November 2019 Published online: 29 November 2019

\section{References}

1. Matsumoto S. Statistical studies on menstruation; a criticism on the definition of normal menstruation. Gunma J Med Sci. 1962;11(4):294-318.

2. MacGregor E, Chia H, Vohrah R, Wilkinson M. Migraine and menstruation: a pilot study. Cephalalgia. 1990;10(6):305-10.

3. Ayele E, Berhan Y. Age at menarche among in-school adolescents in Sawla town, South Ethiopia. Ethiop J Health Sci. 2013;23(3):189-200.

4. Lee S. Health and sickness: the meaning of menstruation and premenstrual syndrome in women's lives. Sex Roles. 2002:46(1):25-35.

5. Dasgupta A, Sarkar M. Menstrual hygiene: how hygienic is the adolescent girl? Indian J Community Med. 2008;33(2):77

6. Wall LL, Belay S, Bayray A, Salih S, Gabrehiwot M. A community-based study of menstrual beliefs in Tigray, Ethiopia. Int J Gynecol Obstet. 2016:135(3):310-3.

7. Sommer M, Ackatia-Armah N, Connolly S, Smiles D. A comparison of the menstruation and education experiences of girls in Tanzania, Ghana, Cambodia and Ethiopia. Compare. 2015;45(4):589-609.

8. Shanbhag D, Shilpa R, D'Souza N, Josephine P, Singh J, Goud B. Perceptions regarding menstruation and practices during menstrual cycles among high school going adolescent girls in resource limited settings around Bangalore city, Karnataka, India. Int J Collaborative Res Intern Med Public Health. 2012;4(7):1353.

9. Adinma ED, Adinma J. Perceptions and practices on menstruation amongst Nigerian secondary school girls. Afr J Reprod Health. 2008;12(1):74-83.

10. Bhatt $\mathrm{R}$, Bhatt M. Perceptions of Indian women regarding menstruation. Int J Gynecol Obstet. 2005;88(2):164-7.

11. Kumar A, Srivastava K. Cultural and social practices regarding menstruation among adolescent girls. Soc Work Public Health. 2011;26(6):594-604.

12. Goel MK, Kundan M. Psycho-social behaviour of urban Indian adolescent girls during menstruation. Australas Med J. 2011;4(1):49.

13. Takeda T, Koga S, Yaegashi N. Prevalence of premenstrual syndrome and premenstrual dysphoric disorder in Japanese high school students. Arch Womens Ment Health. 2010;13(6):535-7.

14. Nwankwo TO, Aniebue UU, Aniebue PN. Menstrual disorders in adolescent school girls in Enugu, Nigeria. J Pediatr Adolesc Gynecol. 2010;23(6):358-63.

15. Halbreich U, Borenstein J, Pearlstein T, Kahn LS. The prevalence, impairment, impact, and burden of premenstrual dysphoric disorder (PMS/PMDD). Psychoneuroendocrinology. 2003;28:1-23.

16. Adewuya A, Loto $O$, Adewumi T. Premenstrual dysphoric disorder amongst Nigerian university students: prevalence, comorbid conditions, and correlates. Arch Womens Ment Health. 2008;11(1):13-8.
17. Omu FE, Al-Marzouk R, Delles H, Oranye NO, Omu AE. Premenstrual dysphoric disorder: prevalence and effects on nursing students' academic performance and clinical training in Kuwait. J Clin Nurs. 2011; 20(19-20):2915-23.

18. Lawan U, Nafisa WY, Musa AB. Menstruation and menstrual hygiene amongst adolescent school girls in Kano, northwestern Nigeria. Afr J Reprod Health. 2010;14(3):201-7.

19. Czerwinski BS. Adult feminine hygiene practices. Appl Nurs Res. 1996; 9(3):123-9.

20. Tegegne TK, Sisay MM. Menstrual hygiene management and school absenteeism among female adolescent students in Northeast Ethiopia. BMC Public Health. 2014;14(1):1118.

21. Fakhri M, Hamzehgardeshi Z, Golchin NAH, Komili A. Promoting menstrual health among Persian adolescent girls from low socioeconomic backgrounds: a quasi-experimental study. BMC Public Health. 2012:12(1):193.

22. Poureslami M, Osati-Ashtiani F. Assessing knowledge, attitudes, and behavior of adolescent girls in suburban districts of Tehran about dysmenorrhea and menstrual hygiene. J Int Women's Stud. 2002;3(2):51-61.

23. Nair M, Chacko D, Darwin MR, Padma K, George B, Russell P. Menstrual disorders and menstrual hygiene practices in higher secondary school girls. Indian J Pediatr. 2012;79(1):74-8.

24. Chandra-Mouli V, Patel SV. Mapping the knowledge and understanding of menarche, menstrual hygiene and menstrual health among adolescent girls in low-and middle-income countries. Reprod Health. 2017:14(1):30.

25. Tangchai K, Titapant V, Boriboonhirunsarn D. Dysmenorrhea in thai adolescents: prevalence, impact and knowledge of treatment. J Med Assoc Thailand. 2004;87(supplement 3):S69-73.

26. Shiferaw MT, Wubshet M, Tegabu D. Menstrual problems and associatedfactors among students of Bahir Dar University, Amhara National Regional State, Ethiopia: a cross-sectional survey. Pan Afr Med J. 2014;17:246

27. Upashe SP, Tekelab T, Mekonnen J. Assessment of knowledge and practice of menstrual hygiene among high school girls in Western Ethiopia. BMC Womens Health. 2015:15(1):84.

28. Adhikari P, Kadel B, Dhungel S, Mandal A. Knowledge and practice regarding menstrual hygiene in rural adolescent girls of Nepal. Kathmandu Univ Med J (KUMJ). 2007;5(3):382-6.

29. Amoo EO, Igbinoba A, Imhonopi D, Banjo OO, Ajaero CK, Akinyemi JO, Igbokwe D, Solanke LB. Trends, Determinants and Health Risks of Adolescent Fatherhood in sub- Saharan Africa. Ethiop J Health Sci. 2018;28(4):433.

30. Chothe V, Khubchandani J, Seabert D, Asalkar M, Rakshe S, Firke A, Midha I, Simmons R. Students' perceptions and doubts about menstruation in developing countries: a case study from India. Health Promot Pract. 2014; 15(3):319-26.

31. Kamaljit K, Arora B, Singh K, Neki N. Social beliefs and practices associated with menstrual hygiene among adolescent girls of Amritsar, Punjab, India. JIMSA. 2012;25(2):69-70

32. Sommer M, Sahin M. Overcoming the taboo: advancing the global agenda for menstrual hygiene management for schoolgirls. Am J Public Health. 2013:103(9):1556-9.

\section{Publisher's Note}

Springer Nature remains neutral with regard to jurisdictional claims in published maps and institutional affiliations.

\section{Ready to submit your research? Choose BMC and benefit from:}

- fast, convenient online submission

- thorough peer review by experienced researchers in your field

- rapid publication on acceptance

- support for research data, including large and complex data types

- gold Open Access which fosters wider collaboration and increased citations

- maximum visibility for your research: over $100 \mathrm{M}$ website views per year

At BMC, research is always in progress.

Learn more biomedcentral.com/submissions 